\title{
РАЗРАБОТКА РУКОВОДЯЩИХ ПРИНЦИПОВ ПОЛИТИКИ ПО СОКРАЩЕНИЮ ГЕНДЕРНОГО РАЗРЫВА В ФИНАНСОВОЙ ИНКЛЮЗИИ НА ГЛОБАЛЬНОМ, РЕГИОНАЛЬНОМ И НАЦИОНАЛЬНОМ УРОВНЯХ
}

\section{DEVELOPING POLICY GUIDELINES TO REDUCE THE GENDER GAP IN FINANCIAL INCLUSION AT THE GLOBAL, REGIONAL AND NATIONAL LEVELS}

G. Makhkamova

Summary. The scientific article is devoted to solving the problems of reducing gender disparities in access to financial services. It has been proven that the presence of gender gaps in financial inclusion (FI) significantly limits the development of economic systems at different levels of their functioning. The aim of the study was to identify the development and implementation of guidelines that will aim to close gender gaps in Fl at the global, international and national levels. The article uses the methods of literary analysis, analysis, synthesis, systematization, grouping and logical generalization, as well as historical and systemic approaches to disclosing and solving the problem of eliminating gender disparities in access to financial services. An assessment of the financial inclusion of women in the world showed that, for most indicators, gender gaps in financial inclusion have not narrowed. A set of policy guidelines have been developed to reduce the gender gap in financial inclusion at the global, regional (Central Asian countries) and national (Republic of Tajikistan) levels. Particular attention is paid to the differences in the development of guidelines at different levels of the functioning of economic systems. Separately, ways of conducting further research in the framework of improving the system of financing small and medium-sized enterprises based on the development of financial inclusion are outlined.

Keywords: gender gap, guidelines, Central Asian countries, Tajikistan, financial inclusion.

\author{
Махкамова Гульбахор Махсудовна \\ К.и.н., Институт экономики и демографии Академии \\ наук Таджикистана, Таджикистан \\ makhkamova.gulbakhor@gmail.com
}

Аннотация. Научная статья посвящена решению проблем сокращения гендерных диспаритетов в доступе к финансовым услугам. Доказано, что наличие гендерных разрывов в финансовой инклюзии (ФИ) значительно ограничивает развитие экономических систем на разных уровнях их функционирования. Целью исследования была определена разработка и реализация руководящих принципов, которые будут направлены на устранение гендерных разрывов в ФИ на глобальном, международном и национальном уровнях. В статье использованы методы литературного анализа, анализа, синтеза, систематизации, группировки и логического обобщения, а также исторический и системный подходы в раскрытии и решении проблематики устранения гендерных диспаритетов в доступе к финансовым услугам. Оценка финансовой инклюзии женщин в мире показала, что по большинству показателей гендерные разрывы в финансовой доступности не уменьшились. Разработана совокупность руководящих принципов политики по сокращению гендерного разрыва в финансовой инклюзии на глобальном, региональном (страны Центральной Азии) и национальном (Республика Таджикистан) уровнях. Особое внимание уделено различиям при разработке руководящих принципов на разных уровнях функционирования экономических систем. Отдельно намечены пути проведения дальнейших исследований в рамках совершенствования системы финансирования предприятий малого и среднего бизнеса на основе развития финансовой инклюзии.

Ключевые слова: гендерный разрыв, руководящие принципы, страны Центральной Азии, Таджикистан, финансовая инклюзия.

\section{Введение}

$\boldsymbol{\Phi}$ инансовая инклюзия (ФИ) получила значительное внимание со стороны практиков и теоретиков, как один из главных путей развития глобальной, международных и национальных экономических систем, в том числе для экономик развивающихся стран $[4 ; 10 ; 13 ; 22]$. Так содействие финансовой доступности стало одним из базовых принципов повестки дня G20 в Давосе в 2020 году [19], что свидетельствует о значительных перспективах роста ФИ в странах мира в будущем. В то же время наблюдается большое количество проблем, мешающих распространению финансовой инклюзии, которые активно трансформируются вместе з изменениями экономических систем на глобальном, международном и особенно национальном уровнях. При этом ключевой проблемой роста финансовой доступности на всех уровнях функционирования экономических систем является проблема гендерного разрыва. 
Таблица 1. Анализ основных показателей финансовой инклюзии женщин в мире за 2011-2017 года

\begin{tabular}{|c|c|c|c|c|}
\hline Показатель & 2011 год & 2014 год & 2017 год & $\begin{array}{l}\text { Абс. отклонение } 2017 \text { год } \\
\text { от } 2011 \text { года }\end{array}$ \\
\hline Счет в банке (население возрастом > 15 лет),\% & 50,6 & 62,0 & 68,5 & 17,9 \\
\hline Счет в банке у женщин (население возрастом > 15 лет),\% & 46,6 & 58,5 & 64,8 & 18,2 \\
\hline $\begin{array}{l}\text { Занимал деньги в прошлом году (население возрастом > } \\
15 \text { лет),\% }\end{array}$ & - & 50,5 & 47,5 & - \\
\hline $\begin{array}{l}\text { Занимал деньги в прошлом году - женщины (население } \\
\text { возрастом > } 15 \text { лет),\% }\end{array}$ & - & 48,2 & 44,9 & - \\
\hline $\begin{array}{l}\text { Занимал деньги в прошлом году в финансовом учреждении } \\
\text { (население возрастом > } 15 \text { лет),\% }\end{array}$ & 9,3 & 10,9 & 10,8 & 1,5 \\
\hline $\begin{array}{l}\text { Занимал деньги в прошлом году в финансовом учреждении } \\
\text { - женщины (население возрастом > } 15 \text { лет),\% }\end{array}$ & 8,4 & 9,8 & 9,4 & 1,0 \\
\hline $\begin{array}{l}\text { Занимал деньги в прошлом году на бизнес (население } \\
\text { возрастом > } 15 \text { лет),\% }\end{array}$ & - & 7,1 & 6,4 & - \\
\hline $\begin{array}{l}\text { Занимал деньги в прошлом году на бизнес - женщины } \\
\text { (население возрастом > } 15 \text { лет),\% }\end{array}$ & - & 5,6 & 5,3 & - \\
\hline Наличие кредитной карты (население возрастом > 15 лет),\% & 14,9 & 17,6 & 18,4 & 3,5 \\
\hline $\begin{array}{l}\text { Наличие кредитной карты — женщины (население возрастом } \\
>15 \text { лет),\% }\end{array}$ & 13,5 & 16,1 & 17,0 & 3,5 \\
\hline Наличие дебетовой карты (население возрастом > 15 лет),\% & 30,7 & 40,6 & 47,7 & 17 \\
\hline $\begin{array}{l}\text { Наличие дебетовой карты — женщины (население возрастом } \\
>15 \text { лет),\% }\end{array}$ & 28,1 & 37,2 & 43,4 & 15,3 \\
\hline $\begin{array}{l}\text { Счет в финансовом учреждении (население возрастом > } \\
15 \text { лет),\% }\end{array}$ & 50,6 & 61,2 & 67,1 & 16,5 \\
\hline $\begin{array}{l}\text { Счет в финансовом учреждении у женщин (население } \\
\text { возрастом > } 15 \text { лет),\% }\end{array}$ & 46,6 & 57,8 & 63,7 & 17,1 \\
\hline $\begin{array}{l}\text { Депозиты в финансовом учреждении (население возрастом > } \\
15 \text { лет),\% }\end{array}$ & 22,4 & 27,3 & 26,7 & 4,3 \\
\hline $\begin{array}{l}\text { Депозиты в финансовом учреждении - женщины (население } \\
\text { возрастом > } 15 \text { лет),\% }\end{array}$ & 20,9 & 25,7 & 24,1 & 3,2 \\
\hline
\end{tabular}

Источник: составлено автором (18)

Поддерживаем точку зрения С. Боухали [6], С. Рао [15], Х.Э. Риваяти [16], что в сегодняшних условиях развития социально-экономических систем как развитых, так и развивающихся стран именно решение проблем финансовой инклюзии и гендерного финансового неравенства являются базисом для обеспечения долгосрочного экономического роста, а также увеличения благосостояния домашних хозяйств, особенно беднейших. В этих условиях важным является разработка и реализация соответствующих принципов, которые будут направлены на устранение гендерных разрывов в ФИ на глобальном, международном и национальном уровнях, что и выступает целью научного исследования.

Исходя из поставленной цели, важным является подтверждение или опровержение таких научных гипотез:

- гендерные разрывы относительно финансовой доступности на уровне мировой экономики снижаются;

- для снижения гендерных разрывов в финансовой инклюзии на глобальном уровне необходима разработка и реализация соответствующих руководящих принципов;

- увеличение доступа женщин к финансовым услугам на региональном уровне (страны Центральной Азии) должно базироваться на разработке и реализации руководящих принципов политики по сокращению гендерного разрыва в финансовой доступности;

- уменьшение гендерных диспаритетов относительно доступа к финансовым услугам на национальном уровне (Таджикистан) должно включать соответствующие руководящие принципы.

\section{Оченка финансовой инклюзии} женшин в мире

Женщины имеют значительные проблемы относительно доступа к финансовым услугам. Приведенная ситуация характерна, как для развитых стран, так и для развивающихся стран и государств с переходной экономикой. Поддерживаем точку зрения международных организаций и иностранных ученых относительно того, 
Руководящие принципы политики по сокращению гендерного разрыва в финансовой доступности на глобальном уровне

\begin{tabular}{|c|}
\hline $\begin{array}{c}\text { Указание четких и количественных целей в рамках реализации политики } \\
\text { женской финансовой инклюзии }\end{array}$ \\
\hline $\begin{array}{c}\text { Формирование полной и объективной базы данных относительно финансовой } \\
\text { инклюзии женщин }\end{array}$ \\
\hline $\begin{array}{c}\text { Реформирование законодательно-нормативной базы для внедрения инноваций } \\
\text { для роста финансовой инклюзии женщин }\end{array}$ \\
\hline $\begin{array}{c}\text { Развитие финансовой инфраструктуры в контексте роста женской финансовой } \\
\text { инклюзии }\end{array}$ \\
\hline $\begin{array}{c}\text { Повышения уровня финансовой безопасности женщин-пользователей } \\
\text { финансовых услуг }\end{array}$ \\
\hline Рост финансового образования и финансовой грамотности для женщин \\
\hline $\begin{array}{c}\text { Устранение в законодательстве социальных норм, сдерживающих } \\
\text { использование женщинами финансовых услуг }\end{array}$ \\
\hline
\end{tabular}

Рис. 1. Руководящие принципы политики по сокращению гендерного разрыва в финансовой доступности на глобальном уровне Источник: составлено автором [2; 3]

что гендерный разрыв в финансовой инклюзии существенно влияет на экономическое положение женщин и сокращает возможности развития для национальных экономических систем [3; 5].

Считаем целесообразным проанализировать основные показатели финансовой инклюзии женщин в мире опираясь на базу данных The Global Financial Inclusion (табл. 1).

Анализ позволяет сделать следующие выводы:

- ни по одному показателю финансовой доступности за все три временных промежутка взятых для проведения исследования женская финансовая инклюзия не была выше общемировой, что свидетельствует о наличии разрывов в ФИ;

- относительно счета в банке, то на фоне положительного тренда показателя, как по миру в целом, так и по женщинам, темпы прироста счета в банке у женщин были выше общемировых, что является положительной тенденцией. Однако значения этого показателя были относительно низкими, как по миру в целом, так и по женщинам весь период исследования;

- отмечаем более низкую кредитную активность женщин в период исследования, которая снизилась к 2017 году по сравнению с 2014 годом, что свидетельствует о проблемах во взаимоотношениях женщин с кредитными организациями (легальными и нелегальными), особенно в развивающихся странах и государствах с переходной экономикой;

- критически низкие значения займов в целом и у женщин в частности в легальных финансовых учреждениях указывают, что большинство кредитных ресурсов женщины привлекают, или у семьи и знакомых, или у нелегальных кредитных организаций; 
- кредитная активность женщин для открытия или развития собственного бизнеса была минимальна весь период исследования и снизилась в 2017 году по сравнению с 2014 годом. Финансовые рынки не могут предложить женщинам инклюзивные кредитные продукты, что является одной из ключевых проблем финансовой инклюзии и развития предпринимательства в мире;

- наблюдается нежелание кредитных учреждений, в первую очередь банков, выдавать кредитные карты женщинам, с другой стороны, недостаточная финансовая грамотность женщин в ряде стран мира не позволяет им пользоваться такими видами финансовых услуг. Наблюдается значительная сегрегация женщин в этой сфере финансовой инклюзии;

- дебетовые карты на фоне кредитных карточек показали рост, как в сегменте ФИ в мире, так и в рамках финансовой доступности для женщин, что еще раз указывает на нежелание банков оказывать кредитную поддержку женщинам и их дискриминацию по гендерному принципу;

- динамика счетов в финансовых учреждениях показала, что большую долю рынка занимают банки, что указывает на проблемы развития финансовых систем на мировом и национальном уровнях, особенно в развивающихся странах и государствах с переходной экономикой, и приводит к росту дискриминации женщин;

- отмечаем низкую депозитную активность женщин и более низкие темпы роста женских депозитов по сравнению с общемировыми тенденциями, что указывает на: проблемы относительно благосостояния женщин, недостаточные возможности (финансовые, имущественные, доступа) для использования депозитных услуг, отсутствие инклюзивных депозитных продуктов банков для женщин.

Акцентируем внимание на то, что за рассмотренный промежуток времени по большинству показателей гендерные разрывы в финансовой доступности не уменьшились, наблюдается даже увеличение разрыва, что требует от международных организаций и национальных правительств разработки и реализации руководящих принципов политики по сокращению гендерного разрыва в финансовой доступности. На сегодняшний момент можно разделить такие принципы на три группы: глобальные; региональные; страновые. При этом они имеют много одинаковых аспектов и положений, но включают определенные отличия исходя из региональных и страновых особенностей развития (экономика, традиции, социальная сфера, развитие общества, культурные аспекты).

\section{РуковоАяшие приншипы политики по сокрашению ген $е$ ерного разрыва в финансовой АОступности на г^обальном уровне}

Считаем целесообразным рассмотреть руководящие принципы политики по сокращению гендерного разрыва в финансовой доступности на глобальном уровне (рис. 1) и дать им характеристику.

Большинство международных организаций и национальных правительств признают наличие гендерного разрыва в финансовой доступности и важность его устранения $[2 ; 17 ; 21]$. При этом значительная часть разрабатываемых политик устранения гендерных разрывов в ФИ, как на глобальном, так и на международном и национальном уровнях носят общий характер без указания четких и количественных целей, что приводит к разбалансированности мероприятий и сложности оценки качества разрабатываемой политики, а также невозможности внести корректирующие изменения. В этих условиях ключевым принципом политики по сокращению гендерного разрыва в финансовой доступности выступает именно четкость и количественное измерение ее целей.

Проблемы доступа женщин к финансовым услугам многообразны и изменяются в рамках регионов мира и отдельных государств, что усложняет разработку эффективной политики, а также действенных мероприятий по устранению гендерного разрыва в ФИ. В этих условиях базисом для разработки и реализации политики по сокращению гендерного разрыва в финансовой доступности женщин должна стать максимально полная информационная база, которая включает объективную информацию. Отмечаем современные значительные проблемы относительно формирования информационных баз в этой сфере ФИ, особенно по объемам информации и ее объективности в развивающихся странах и государствах с переходной экономикой. Таким образом, данный принцип является ключевым для политики по сокращению гендерного разрыва в финансовой доступности на глобальном уровне.

Существующие финансовые системы на мировом, международном и национальном уровнях не позволяют решить проблемы гендерного разрыва в финансовой доступности, что требует внедрения инноваций, в том числе с использованием цифровых инновационных финансовых технологий. Однако для этого требуется реформирование законодательно-нормативной базы для устранения препятствий относительно разработки и внедрения инноваций в этой сфере.

Специфика экономической жизни и активности женщин требует реформирования и развития финансовой 
инфраструктуры с целью повышения их доступа к финансовым услугам, где особое внимание необходимо уделить инклюзивному подходу к решению финансовых проблем женщин, а также ограниченности их мобильности из-за необходимости вести домашнее хозяйство и осуществлять уход за детьми, родителями или другими родственниками.

Рост сложности финансовых услуг, недостаточный контроль за безопасностью на рынках финансовых услуг, активное использование асимметрии информации контрагентами женщин в финансовой сфере снижает уровень их финансовой безопасности, а также желание пользоваться финансовыми услугами. Отдельно отмечаем проблемы с доступом к легальным поставщикам финансовых услуг у женщин в ряде развивающихся стран и государств с переходной экономикой. В этих условиях повышение уровня финансовой безопасности женщин-пользователей финансовых услуг выступает руководящим принципом политики по сокращению гендерного разрыва в финансовой доступности на глобальном уровне.

Финансовое образование и финансовая грамотность являются ключевыми аспектами в успешном использовании любых финансовых услуг или продуктов, а также снижают риски для пользователей. В сегодняшних условиях, когда женщины имеют меньшие возможности на рынках финансовых услуг, недостаточное финансовое образование или пробелы в финансовой грамотности приводит к сокращению использования финансовых услуг или продуктов, особенно, тех, которые базируются на цифровых инновационных финансовых технологиях [3]. Таким образом, данный принцип является ключевым для разработки и реализации политики по сокращению гендерного разрыва в ФИ на глобальном уровне.

Значительное количество стран мира имеют в законодательной базе нормы, которые усугубляют социальные проблемы и сегрегацию женщин в финансовой сфере, что делает устранение таких норм одним из руководящих принципов политики по сокращению гендерного разрыва в финансовой доступности на мировом уровне.

Региональные руководяшие приншипы политики по сокрашению генАерного

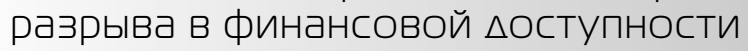

Страны Центральной Азии (ЦА) имеют значительные проблемы относительно гендерного разрыва в финансовой доступности [8; 14]. При этом эти проблемы частично повторяют общемировые, а частично носят региональный характер, что подразумевает выделения региональных руководящих принципов политики по со- кращению гендерного разрыва в финансовой доступности (рис. 2) и характеристики их.

Отмечаем, что второй, пятый, восьмой и частично девятый руководящие принципы идентичны таким же принципам в глобальном масштабе. В то же время страны Центральной Азии нуждаются в разработке стратегий реализации политики по сокращению гендерного разрыва в финансовой доступности, поскольку в современных условиях их деятельность зачастую носит хаотичный и бессистемный характер, влияние на которую оказывают инициативы отдельных международных организаций, частных институтов и государственных органов, что не позволяет получить долгосрочный устойчивый рост женской финансовой инклюзии.

Значительной проблемой на пути роста женской ФИ является недоверие к национальным финансовым учреждениям. Трансформационные процессы, которые происходят в финансовых системах стран Центральной Азии периодически порождают кризисы или появление на рынке мошеннических структур, что подрывает доверие к системам и их субъектам со стороны женщин, которые больше подвержены рискам из-за своего слабого имущественного состояния и более низкой финансовой грамотности [8]. В этих условиях задачей международных доноров, государственных институтов и самих финансовых учреждений является устранение негативных аспектов в этой сфере.

Важнейшим из принципов на пути сокращения гендерного разрыва в финансовой доступности в странах Центральной Азии является имплементация зарубежного опыта, поскольку с большинством проблем женской ФИ сталкиваются другие страны и наработан значительный опыт их решения. При этом важным является переосмысление зарубежного опыта и его эффективная интеграция в финансовые системы стран ЦА.

Учитывая особенности развития финансовых систем стран Центральной Азии и высокую долю во многих из них доходов эмигрантов и трудовых мигрантов, отмечаем наличие значительных теневых рынков, которые успешно конкурируют с официальными рынками финансовых услуг. При этом женщины, которые менее финансово грамотны и испытывают значительную дискриминацию на официальных рынках финансовых услуг, активно пользуются услугами теневого рынка, подвергая себя рискам и неся дополнительные транзакционные расходы на осуществление операций [14]. Приведенная ситуация требует устранения на пути сокращения гендерного разрыва в финансовой доступности в странах ЦА.

Проблематика недоверия национальным финансовым учреждениям и необходимость уменьшения доли 


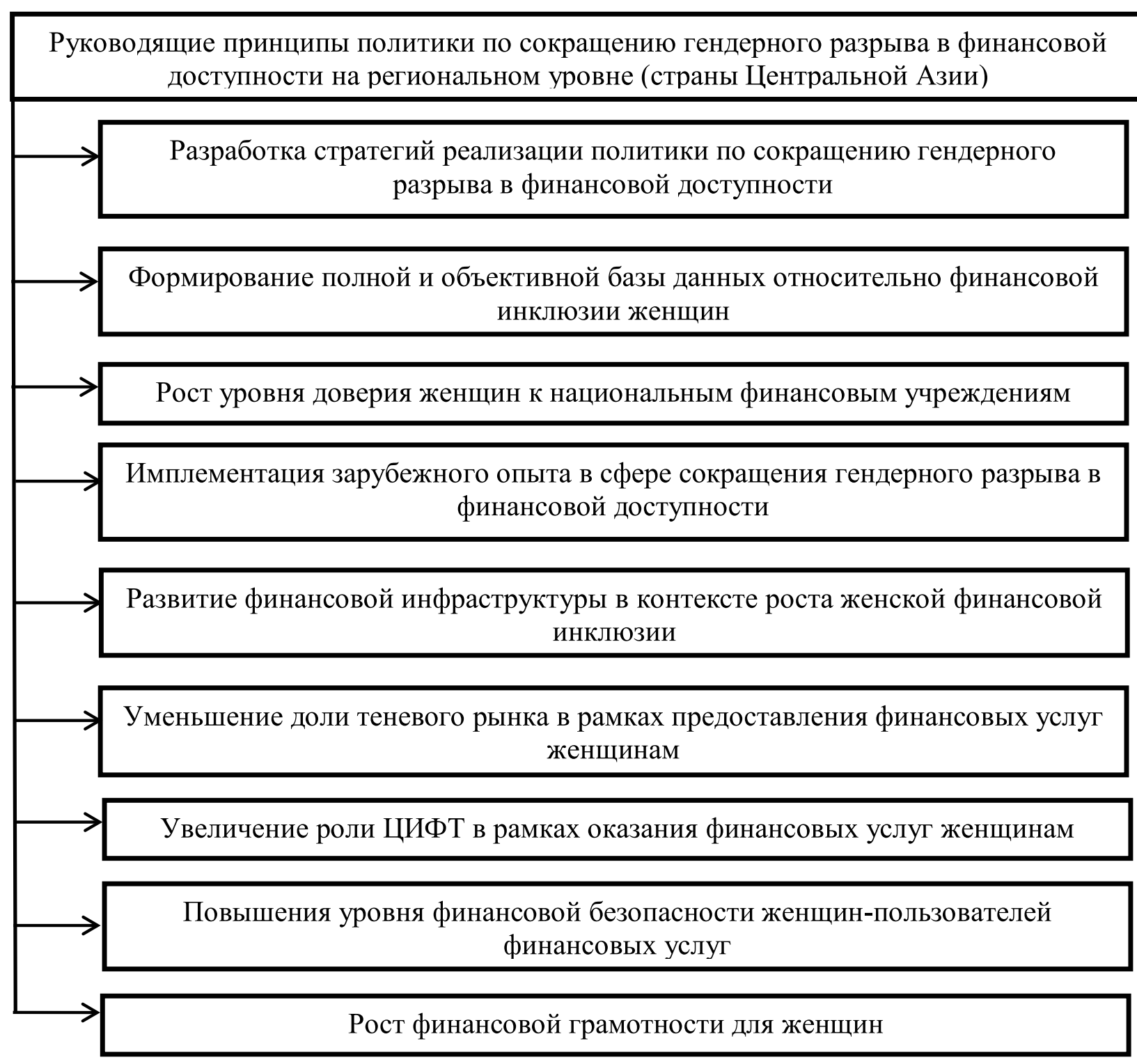

Рис. 2. Руководящие принципы политики по сокращению гендерного разрыва в финансовой доступности на региональном уровне (страны Центральной Азии)

Источник: составлено автором [8; 14]

теневого рынка финансовых услуг в контексте роста женской финансовой инклюзии, а также значительный образовательный уровень женщин в странах Центральной Азии и большие возможности использования Интернета и мобильной связи [18] позволяют более широко использовать цифровые инновационные финансовые технологии для сокращения гендерного разрыва в финансовой доступности.

Отдельно отмечаем, что перед странами ЦА стоит проблема роста финансовой грамотности женщин, поскольку развитие образовательных систем этих стран и возможности учиться за рубежом, особенно в Россий- ской Федерации, не ставят остро проблему финансового образования для женщин, которая существует во многих развивающихся странах. В то же время уровень финансовой грамотности женского населения стран Центральной Азии требует интенсификации усилий в рамках его повышения.

\section{Выво $\triangle$}

Финансовая инклюзия является важной составляющей обеспечения устойчивого роста мировой, международных и национальных экономических систем. Наличие значительных гендерных диспаритетов в до- 
ступе к финансовым услугам выступает одним из ключевых факторов, который не позволяет в полной мере использовать экономический потенциал ФИ, особенно, что касается развивающихся стран и государств с транзитивной экономикой. Такая ситуация требует проведения дополнительных исследований и проверки ряда гипотез.

Гендерные разрывы относительно финансовой доступности на уровне мировой экономики не демонстрируют устойчивых тенденций к снижению, а в некоторых случаях наблюдается их рост (кредитование женщин, кредитование бизнеса женщин-предпринимателей). Приведенное опровергает первую гипотезу научного исследования.

Для формирования политики по сокращению гендерных разрывов в финансовой инклюзии на глобальном уровне необходима реализация совокупности руководящих принципов, которые подходят, как для развитых, так и для развивающихся стран, а также государств с переходной экономикой.

Учитывая особенности развития экономических систем стран из отдельных регионов мира, необходимой является разработка руководящих принципов политики по сокращению гендерных разрыва в финансовой доступности на региональном уровне, что позволило доказать третью гипотезу исследования на примере стран Центральной Азии.

Уменьшение гендерных диспаритетов относительно доступа к финансовым услугам на национальном уровне должно опираться на разработанные руководящие принципы на мировом и региональном уровне, а также учитывать приоритеты экономического развития отдельных государств, что требует разработки и реализации дополнительных руководящих принципов политики по сокращению гендерного разрыва в финансовой доступности. Данная гипотеза была доказана в исследовании на примере Республики Таджикистан.

Учитывая приведенное, можем подтвердить, что цель исследования была достигнута. Ключевой ценностью статьи является разработка совокупности руководящих принципов, направленных на устранение гендерных разрывов в ФИ на глобальном, междуна- родном и национальном уровнях. В связи с этим можно выделить некоторые ограничения в использовании результатов статьи, а именно необходимость: разработки базовых направлений совершенствования системы финансирования предприятий малого и среднего бизнеса на основе развития финансовой инклюзии, с акцентом на ФИ бизнеса женщин-предпринимателей на примере отдельных стран мира. В то же время, приведенные ограничения не снижают научно-практическую ценность данной статьи и характеризируют в большей степени перспективы проведения дальнейших научных исследований.

\section{Зак^ючение}

Проведенное исследование позволило выявить наличие значительных диспаритетов относительно доступа к финансовым услугам женщин в мире, а также подтвердить необходимость разработки и реализации политики по сокращению гендерных разрывов в финансовой инклюзии. В этих условиях разработка политики по повышению доступа женщин к финансовым услугам должна проводиться на глобальном, региональном и национальном уровнях и опираться на совокупности соответствующих руководящих принципов.

Разработанная совокупность руководящих принципов политики по сокращению гендерного разрыва в финансовой доступности на глобальном, международном (страны Центральной Азии) и национальном (Таджикистан) уровнях позволит ускорить процессы финансовой интеграции женщин, а также уменьшить ограничения на доступ женщин, в том числе женщин-предпринимателей, к финансовым услугам.

Практическое внедрение предложений и выводов данной статьи следует рассматривать в контексте обеспечения устойчивого роста экономических систем, в первую очередь для развивающихся стран и государств с транзитивной экономикой.

Перспективы дальнейших исследований на основе и с использованием научных результатов статьи состоят в разработке путей совершенствования системы финансирования предприятий малого и среднего бизнеса на основе развития финансовой инклюзии для отдельных стран мира.

\section{ЛИТЕРАТУРА}

1. AFI. 2018 Maya Declaration progress report. [Электронный ресурс] — Режим доступа: https://www.afi-global.org/sites/default/files/publications/2018-09/ AFI_Maya_report_2018_AW_digital.pdf.

2. AFI. Bridging the Gap: Financial Inclusion for Gender and Women. [Электронный ресурс] — Режим доступа: https://www.afi-global.org/bridging-gap-financialinclusion-gender-and-women. 
3. AFI. Policy frameworks to support women's financial inclusion / AFI. — Kuala Lumpur: Alliance for Financial Inclusion, 2016. - $24 \mathrm{p}$.

4. Allen F. The African financial development and financial inclusion gaps. / F. Allen, E. Carletti, R. Cull, J. Qian, L. Senbet, P. Valenzuela// Journal of African Economies. 2014. — № 23(5).—pp. 614-642.

5. Arnold J., Gammage S. Gender and financial inclusion: the critical role for holistic programming/ J. Arnold, S. Gammage // Development in Practice.— 2019. № 29(8).- - pp. 965-973.

6. Boukhali S. Women's Financial Inclusion / S. Boukhali // SDC. - 2019. — pp. 1-8.

7. Demirguc-Kunt A. Financial Inclusion and Legal Discrimination Against Women. Evidence from Developing Countries / A. Demirguc-Kunt, L. Klapper, D. Singer // Development Research Group. Finance and Private Sector Development Team. — 2013. — Policy Research Working Paper 6416. — pp. 1-47.

8. Demirguc-Kunt A. Financial Inclusion in Europe and Central Asia — the Way Forward? / A. Demirguc-Kunt and Cyril Muller // The World Bank. — 2019. ГЭлектронный ресурс] — Режим доступа: https://www.worldbank.org/en/news/opinion/2019/04/05/financial-inclusion-in-europe-and-central-asia-the-way-forward.

9. Honohan P. Cross-Country Variation in Household Access to Financial Services/ P. Honohan // Journal of Banking \& Finance, Elsevier. — 2008. — № 32(11). — pp. 2493-2500.

10. lanchovichina E. Inclusive Growth Analytics. Framework and Application. / E. lanchovichina, S. Lundstrom // The World Bank. — 2009.—Policy Research Working Paper 4851. - pp. 1-42.

11. Jain S. Bridging the gender gap: Fintech as a means to empower women / S. Jain // ORF.— 2019. [Электронный ресурс] — Режим доступа: https://www. orfonline.org/expert-speak/bridging-the-gender-gap-fintech-as-a-means-to-empower-women-58365.

12. Kim M. et al. Mobile financial services, financial inclusion, and development: A systematic review of academic literature/ M. Kim et al. //The Electronic Journal of Information Systems in Developing Countries. — 2018.— № . 5 (84) — pp. 1-17.

13. Kokorović Jukan M. Comparative analysis of financial inclusion in developing regions around the world / M. Kokorović Jukan, A. Softić // Journal of Economics and Busines. — 2016. — № 14 (2). — pp. 56-65.

14. Morgan P.J. Overview of financial inclusion, regulation, financial literacy, and education in Central Asia and South Caucasus / P.J. Morgan, Y. Zhang, and D. Kydyrbayev// ADBI Working Paper Series. — 2018. — № 878. — pp. 1-36.

15. Rao S. Gender and financial inclusion through the post / S. Rao // UN Women. - 2015. - pp. 1-50.

16. Riwayati H.E. Financial Inclusion of Business Players in Mediating the Success of Small and Medium Enterprises in Indonesia / H.E. Riwayati // International Journal of Economics and Financial Issues. — 2017 — № 7(4).—pp. 623-627.

17. Stotsky J.G. Trends in gender equality and women's advancement/ J.G. Stotsky, S. Shibuya, L. Kolovich and S. Kebhaj. — Washington, DC: IMF, 2016. — 62 p.

18. The World Bank. Global Financial Inclusion. DataBank. [Электронный ресурс] — Режим доступа: https://databank.worldbank.org/reports.aspx?source=1228\#.

19. The World Economic Forum. World Economic Forum Annual Meeting. [Электронный ресурс] — Режим доступа: https://www.weforum.org/events/worldeconomic-forum-annual-meeting-2020\#themes.

20. UNECE. Национальный обзор Республики Таджикистан по осуществлению Пекинской декларации и платформы действий (1995 года) в рамках внедренной повестки дня в области устойчивого развития на период до 2030 года и итоговых документов двадцать третьей специальной сессии генеральной ассамблеи (2000 года) в контексте двадцать пятой годовщины четверной всемирной конференции по положению женщин и принятия пекинской декларации и платформы действий в 2020 году. [Электронный ресурс] — Режим доступа: https://www.unece.org/fileadmin/DAM/RCM_Website/Tajikistan.pdf.

21. USAID. Women's economic empowerment. [Электронный ресурс] — Режим доступа: https://www.usaid.gov/what-we-do/gender-equality-and-womensempowerment/womens-economic-empowerment.

22. Zins A. The determinants of financial inclusion in Africa / A. Zins, L. Weill // Review of Development Finance.— 2016.— № 1 (6).—pp. 46-57. 